\title{
Abstraction and embodiment: exploring the process of grasping a general
}

\author{
Svanhild Breive ${ }^{1}$ D
}

Accepted: 13 December 2021 /Published online: 12 January 2022

(c) The Author(s) 2021

\begin{abstract}
This paper reports from a case study which explores kindergarten children's mathematical abstraction in a teaching-learning activity about reflection symmetry. From a dialectical perspective, abstraction is here conceived as a process, as a genuine part of human activity, where the learner establishes "a point of view from which the concrete can be seen as meaningfully related" (van Oers \& Poland Mathematics Education Research Journal, 19(2), 10-22, 2007, p. 13-14). A cultural-historical semiotic perspective to embodiment is used to explore the characteristics of kindergarten children's mathematical abstraction. In the selected segment, two 5-year-old boys explore the concept of reflection symmetry using a doll pram. In the activity, the two boys first point to concrete features of the sensory manifold, then one of the boys' awareness gradually moves to the imagined and finally to grasping a general and establishing a new point of view. The findings illustrate the essential role of gestures, bodily actions, and rhythm, in conjunction with spoken words, in the two boys' gradual process of grasping a general. The study advances our knowledge about the nature of mathematical abstraction and challenges the traditional view on abstraction as a sort of decontextualised higher order thinking. This study argues that abstraction is not a matter of going from the concrete to the abstract, rather it is an emergent and contextbound process, as a genuine part of children's concrete embodied activities.
\end{abstract}

Keywords Abstraction $\cdot$ Embodiment $\cdot$ Rhythm $\cdot$ Gestures $\cdot$ Early years mathematics education $\cdot$ Reflection symmetry

\section{Introduction}

The significance of the body in the development of human cognition has gained increasing focus in diverse fields of psychology and raised the prominence given to the role of the body in the formation of concepts, including mathematical concepts. Within mathematics education research, various theoretical perspectives to embodiment have emerged, such as the theory of embodied mathematics (e.g., Núñez et al., 1999), the theory of mathematics in the flesh (e.g., Roth, 2011; Thom \& Roth, 2011), sensuous cultural-historical

Svanhild Breive

svanhild.breive@uia.no

1 University of Agder, Kristiansand, Norway 
cognition (e.g., Radford, 2009, 2013, in press), and inclusive materialism (de Freitas \& Sinclair, 2014), to mention some of the contributors to this area. Except for, perhaps, the rather moderate perspective by Núñez et al. (1999), the other, more radical, approaches to embodiment aim to erase the body-mind dualism that has been prominent in cognitive psychology in the past and the long-standing assumption that thinking is a purely mental activity, immaterial and independent of the body. In the more radical approaches, mathematics is not considered a body of transcendental ideas, but as part of concrete human activity, dependent on bodily and sensuous experience. As a consequence of the increased focus on embodiment, the role of gestures in and for thinking has also gained attention in educational research and has been found important in the formation of mathematical concepts, for example, in teaching-learning about spatial concepts (Elia \& Evangelou, 2014), numerical relations (Sabena, 2018), and algebraic structures (Radford, 2009). Despite the increasing focus on the role of the body in mathematics thinking and learning, and the acceptance that young children use artefacts and gestures while solving mathematical tasks, the literature is still sparse on the more precise role of the body in young children's mathematical thinking. Thus, it is necessary to further scrutinise the roles played by gestures, artefacts, and other bodily means in children's mathematical thinking and in the teaching-learning of mathematics.

Traditionally, learning mathematics is often seen as a progressive movement or trajectory from the concrete and sensible to the abstract. Moreover, mathematical thinking has often been considered in a hierarchy with levels of abstractions, where "at a higher and more abstract level," knowledge is "created by recognising similar core features" and is "less tied to specific contexts" (Hiebert \& Lefevre, 1986, p. 4-5). However, this classical view of abstraction as a higher order category of decontextualised relations that captures the metaphysical essence of "things" has been criticised by many (e.g., Hershkowitz et al., 2001; Ozmantar \& Monaghan, 2007; van Oers \& Poland, 2007). Prior to these studies, Noss et al. (1997) argued, from a constructionist perspective, that

abstracting - considered as a process - can be seen as a way of layering meanings on each other, rather than as a way of replacing one kind of meaning (concrete, referential) with another (abstract, decontextualised). The emphasis is on connections between ways of knowing and seeing, rather than on the replacement of one by another (p. 226)

From a dialectical perspective (Davydov, 1972/1990), there is a deep interconnection between the concrete and the abstract. In this perspective, the process of abstraction is a genuine part of human activity where the abstract and the concrete mutually constitute each other. Following Davydov, Hershkowitz et al. (2001) argue that the abstraction process is not a matter of going from the concrete to the abstract, rather a process where the unity of the abstract and concrete moves from an undeveloped to an elaborated form "in which new features of the concrete are emphasised" (p. 200). The authors consider abstraction as "an activity of vertically reorganising previously constructed mathematics into a new mathematical structure" (p. 202). They argue that the genesis of an abstraction starts with a need for a new structure and is constructed via three nested epistemic actions, namely (R)ecognising, (B)uilding-with, and (C)onstructing; this is called the RBC model. Recognising refers to the identification of already familiar mathematical structures, which are results from of earlier abstractions. Building-with refers to the combination of familiar or available mathematical structures in achieving a goal such as solving a problem. Constructing refers to the configuration of structures in producing a novel mathematical structure. They also introduce the term consolidation, which captures how the abstracted 
is recognised with increased ease in future activities and can be used in further abstractions. Building on Hershkowitz et al. (2001), Ozmantar and Monaghan (2007) argue that "[a]bstraction is a process of making sense of [...] concrete situations by discovering new meaning in order to establish interconnections amongst the different elements of the whole" (p. 92). For them, consolidation is important, as the new construction is fragile and needs to be consolidated to become a product of abstraction. Another approach, also grounded in a dialectical perspective, is advocated by van Oers and Poland (2007), who define abstraction as " $a$ process of constructing relationships between objects from a particular point of view" (p. 13, emphasis in origin). Abstractions are part of contextualised human activity which "always includes taking a point of view from which the concrete can be seen as meaningfully related" (ibid., p. 13-14).

Although there is increasing attention for both embodiment and abstraction, it can be argued that the link between them is undertheorised. An exception is, for example, Nemirovsky et al. (2020), which investigates how 11-year-old students attain abstraction through their body motions while working on a pre-algebra problem $(\mathrm{A}-\mathrm{B}=\mathrm{C})$, using a motor detector. They conceive abstracting as "navigating a plane of sensorimotor qualities" (p. 263). In a similar, but not identical, vein, this study aims to investigate abstraction through the lens of an embodied cognition perspective and thus to link theories of abstraction and embodiment. In this study, I align with Radford's (2009, 2013, in press) materialist approach to embodiment (which I elaborate below) and regard gestures, as well as rhythm and other bodily means, as "genuine constituents of thinking" (Radford, 2009 p. 113, emphasis in original); thinking does not unfold behind bodily activity but is part of bodily activity itself. From a dialectical perspective, abstraction is here conceived as a process, as genuine part of human activity, where the learner establishes "a point of view from which the concrete can be seen as meaningfully related" (van Oers \& Poland, 2007 , p. 13-14). This new perspective is a sensuous awareness that continuously emerges and changes through activity. Moreover, the new perspective is dialectically related to the child's actions (including its physical movements). The actions and the perception continuously constitute and guide each other.

Nemirovsky et al. (2020) distinguish between two types of abstractions: "navigating to grasp a general and navigating to solve something vaguely known" (p. 265). In my study, I focus on abstraction as a process of grasping a general, where a general is seen as an indeterminate category, for example, a triangle, which is not specified as, say isosceles or equilateral (or whatever), is general. "'Triangles', as a general, refers to a multiplicity of items that are all actively related to each other through a continuous and mutual communication of differences" (Nemirovsky et al., 2020, p. 265, emphasis in origin). In this case, I specifically focus on a general produced through a generalisation, which means produced through "extending a finite set of empirical observations" (ibid., p. 265). The research question formulated to guide this study is: What characterises the process of grasping a general? The question is applied to a case where two boys, John and Elias, ${ }^{1}$ together with their kindergarten teacher (KT), explore the concept of reflection symmetry.

In the following sections, I first present the cultural-historical semiotic perspective that guides my study and how embodiment may be seen in this perspective. This section is followed by sections on the role of rhythm in mathematical thinking and human symmetry

\footnotetext{
1 All names of the people in this paper are pseudonyms.
} 
perception. I then present the methodological approach, the segment, and the analysis. I end the paper with a discussion and concluding remarks.

\section{Embodiment within a cultural-historical perspective}

To be useful for pedagogical investigations, the idea of the embodied mind must be aligned with a theoretical perspective on teaching and learning. As mentioned in the introduction, a central argument within the embodied cognition approach to education is that humans relate to, and make sense of, the world through multiple sensuous modes (visual, auditory, kinaesthetic, tactile). From a cultural-historical perspective, mathematical objects are cultural-historical systems of meanings that exist as potentials in the culture. These potentials are not directly sensible and must be made sensible to the learner through activity (Radford, in press). Activity is an ever-changing process, a system of relations that unfolds through concrete human actions. These actions may be seen as signs that each plays an important role in making the mathematical objects sensible. Cultural artefacts are also considered essential in this process, as they, in the use of an agent, are things that may signify something for others. It is through the coordination of various materials, bodily and sensuous means that mathematical thinking is brought to life, i.e., materialised, and made sensible to the learner. According to Radford (in press), "[e]mbodiment, in short, is the name of the activity-based dialectical relationship between sensing subjects and the cultural-historical sensed objects" (p. 18).

The use of semiotic means is linked to various semiotic sign systems (e.g., written text, verbal language, mathematical symbolism). As children develop, they encounter various semiotic systems and conventional forms of using signs and must learn to move flexibly between systems. However, this is not necessarily a straightforward process. Radford, for example, has, for many years, investigated how students move from pre-symbolic to symbolic generalisations, and thus between different semiotic sign systems, in the context of pattern activities (e.g., Radford, 2008, 2010, 2013, 2015, 2018). He has especially focused on how the coordination of speech, bodily actions, gestures, rhythm, symbols, and tools plays a role in moving through different levels of generalisation. Radford illustrates how students' awareness of the algebraic structures increases when students move from what he calls factual generalisation, where gestures are leading the activity, to contextual generalisation, where language is leading and gestures recede into the background, and finally to symbolic generalisation where symbols are taking the lead. An essential feature of this process is what Radford $(2008,2013,2018)$ calls semiotic contraction. As the subject becomes more aware of the object, the use of semiotic means contracts into a more refined and compact unity. For example, a complex arrangement of gestures, words, rhythm, and tools may be replaced with a sentence, a general term, and perhaps later with a symbolic expression. What is essential to the process of contraction is that the previous activity does not disappear, "Behind language [...] there still resonates the complex bodily, material, and semiotic activity of the previous sensuous actions and forms of sensing" (Radford, 2013, p. 160).

In a similar vein to Radford's exploration as to how generalisations appear within different sign systems, Thom and Roth (2011) argue that the relation between the sign and the signifier can operate on different levels. They explore how this relation occurs first on the sensory level and later on the linguistic level when an 8-year-old boy, Owen, explains the differences between two wooden blocks (a long, narrow rectangular prism and a short, wide (i.e., more quadratic) prism). Although Owen had problems explaining the 
differences verbally, he articulated the differences by touching and gesturing on the blocks. Thus, young children seem to have mathematical insights without being able to articulate them verbally or symbolically. Moreover, gestures and other bodily means seem to play a crucial role in flexibly moving from one semiotic system to another.

\subsection{Rhythm}

Rhythm is another semiotic means that is found essential in the construction of mathematical concepts. Rhythm is a central feature of nature and of human existence. Rhythm is found in the continuous repetition of sunset and sunrise and in the changing of seasons; found in the pulsing of heartbeats and in the cyclic changes of hormones; and part of our everyday movements, for example, walking, cycling, or swimming. No wonder that, in recent times, rhythm is also found as a fundamental structuring feature of mathematical thinking, for example in counting and formation of number sense (e.g., Breive, 2019; Sinclair et al., 2016), spatial and geometrical understanding (e.g., Bautista \& Roth, 2012; Roth, 2011), proportional understanding (Palatnik \& Abrahamson, 2018), and in understanding of algebraic structures (e.g., Radford, 2010, 2013, 2015).

Rhythm is argued to be primarily temporal and material. Roth (2011), for example, argues that "[r]hythm can be understood as the production of form under the constraints of time and temporality" (p. 156). Rhythm may therefore be seen as temporal recurrence of "something," like recurrence of sound/silence in speech coordinated in time. Radford (2015) argues that "[i]n its general sense, the concept of rhythm tries to characterise the appearance of something at regular intervals and attempts to capture the idea of regularity, alternation, or something oscillating between symmetry and asymmetry" (p. 68). Rhythm mediates several things, and one of the most important elements of rhythm is what Radford call "theme." "Theme is the very important component of rhythm that moves us from memory to imagination and that provides us with the feeling of continuity of the phenomenon under scrutiny - the sense that something will happen next, or the expectation of a forthcoming event" (Radford, 2015, p. 81).

Rhythm seems fundamental not just for mathematical thinking but for human communication and interaction in general. Roth (2011) argues that rhythmic phenomena make interaction possible. He attends to the way in which "[r]hythmic features structure the ways in which we communicate and, therefore, structure the ways in which we interact with others" (p. 160). For example, when studying kindergarten children's problem-solving processes when working with addition problems, Breive (2020) found that rhythm was both a condition and an outcome of turn taking in mathematical conversations; rhythm was central in structuring children's turn taking, but at the same time, turn taking gave rise to a rhythmic counting and thus materialised multiplicative structures. Similarly, Sinclair et al. (2016) argues that rhythm is a social phenomenon. They explore the affective, social, and mathematical dimensions when children (ages 6,7, and 8) use an iPad application to experience numbers. They show how various rhythms emerge, and change over time, and how children move from the particular to the general.

\subsection{Symmetry perception}

The study reported here investigates a case involving the mathematical concept of reflection symmetry (or mirror symmetry). A physical object has reflection symmetry if there is at least one line (in 2D) or one plane (in 3D) that divides the object into two halves 
such that one half is the mirror image of the other half. Research indicates that humans, from a very young age, are sensitive to reflection symmetry (Treder, 2010). Research also indicates that our capacity to detect symmetry is constantly used to structure our visual input. Treder (2010) points out that "a striking characteristic of symmetry is that it seems to impose structure when viewed by an observer" (p. 1513). Thus, symmetry seems to be an organising means for how human visually perceive the material world. Without the ability to detect differences and similarities and symmetries and asymmetries, the world would be a sensory mess. "The world in front of us would be reduced to myriads of single and incommensurable facts: everything would be different from everything else and resemblances between things would be impossible to imagine" (Radford, 2010, p. 2). However, as humans are enveloped in cultural meanings, we cannot assume that our visual perception remains unchanged throughout life. Rather, visual perception seems to develop in conjunction with other sensorial organs in response to the ever-changing cultural-historical context we live in and thus affects the way we see the world. Radford (2010) argues that "what we see is not the result of direct inputs but of stimuli already filtered by meanings and information about objects and events in the world - meanings conveyed by language and other cultural semiotic systems" (p. 2). According to this view, the way older children come to perceive reflection symmetry mathematically and culturally is different from how they perceive reflection symmetry as infants.

Another pertinent issue, which Arnheim (1969) points to, is the tension between how we perceive symmetry and how we describe it. As mentioned above, we seem to appreciate visual symmetry as a whole; however, when describing symmetry, the linearity of speech does not allow us to refer simultaneously to two different points, rather a symmetrical interaction between two entities is transformed into one entity that interacts with the other entity.

\section{Methodology}

The case discussed in this paper stems from a Norwegian research and development project, the Agder Project, and I use data from a previously published paper (Breive, 2017). In Norway, children attend kindergarten from ages 0.5 to 6.5. The segment examined in this study is selected from a whole-group session where one kindergarten teacher (KT) and a group of six 5-year-old children engage in a mathematical pre-school activity ${ }^{2}$ about reflection symmetry.

The segment involves two boys, John and Elias, explaining why a doll pram has reflection symmetry (or, as the KT says, is equal on two sides). The segment was selected because of its suitability for the focus of this paper; the role of rhythm, gestures, and other bodily means in young children's abstraction (in the sense described in the "Introduction") of reflection symmetry. The selected segment was transcribed, ${ }^{3}$ focusing on the sequence of bodily actions (e.g., gestures, hand movements, and the use of artefacts) corresponding to verbal utterances.

To investigate the development of signs in activity, one can draw on the construct of semiotic bundle (Arzarello et al., 2009), which is defined as

\footnotetext{
2 The term activity is here used in an everyday sense, not in an activity theory sense.

3 The segment was transcribed in Norwegian and later translated into English.
} 
a dynamic structure (the signs and their relationships) which can change in time because of the semiotic activities of the subjects. Its relationships can be of different types. A first type concerns those signs produced at the same time, such as when the subject gesticulates and speaks simultaneously. Other relationships concern signs produced at different (near or far) times, for example signs that are transformed into other signs (Arzarello et al., 2009, p. 100).

The two types of relationships (events at a point in time and events over time) give rise to two analytical perspectives: a synchronic and a diachronic perspective, respectively (Radford \& Sabena, 2015). My interpretation of the segment considers both synchronic and diachronic relations. The two analytical perspectives fed on each other in a dialectic way, but in this paper, I present them in a linear order. I present first the synchronic analysis because it reveals how gestures, speech, and use of artefacts, together, in momentto-moment coordination, create meaning. For example, what meaning is created when a word is used in conjunction with a specific gesture. Then I present the diachronic analysis in order to explore the movement of the whole activity and what facilitates Elias' move into the imaginary and the establishment of a new point of view. The diachronic analysis reveals how signs and their relations evolve over time and what meaning is then created; the diachronic analysis is thus particularly important for capturing rhythm.

\section{The segment: making sense of reflection symmetry}

In the communication that precedes the segment, the KT introduces the activity by using a mirror. He gives the children one mirror each and some geometrical shapes and encourages the children to play with them. He then introduces a sketch that illustrates the right side of a mouse's face. He uses a mirror to show how he can make a whole face by mirroring the sketch. He emphasises that the mouse's face is "equal on both sides." Then he shows how all the children's faces are also "equal on both sides," by pointing out that they all have one eye on each side and one ear on each side. When he illustrates the symmetry, he stands behind each child simultaneously pointing with the left index finger on the left side and with the right index finger on the right side. He does not explicitly talk about the symmetry line, but the line is visualised by, for example, the intersection between the mirror and the paper with the sketch on. All in all, the KT comments on many aspects of reflection symmetry, but this does not mean that all aspects are necessarily perceived by the children. I would like to note that the KT does not, explicitly, talk about how each point on one side of the symmetry line has a corresponding point on the other side of the symmetry line. By "corresponding points," I mean two points that are on a line perpendicular to the symmetry line or to the symmetry plane and that lie in an equal distance from the symmetry line/ plane.

Then the KT asks the children to find toys in the room which they think are "equal on two sides" and bring them back to the table. Each child is then asked to explain why they think the toy they have chosen is equal on both sides. In this particular segment, one of the boys (John), who has chosen a doll pram, is asked to explain why he thinks the doll pram is equal on both sides (or, more precisely, he is asked if he thinks the trolley is equal on both sides). 
$1 \mathrm{KT}$ : Maybe we should start with John, since he has a very large thing. John, is this equal on two sides?

2 John: Mmm (He lifts his trolley up from the table and holds it in a straightforward position, Fig. 1a). There. (He nods his head while he says "there." Then he rotates the doll pram 90 degrees, showing the side of the doll pram, Fig. 1b) and there (pause) and ...

3 KT: Aha!

4 John: (John rotates the trolley 180 degrees, showing the other side of the doll pram, Fig. 1c) there.

5 Elias: And there and there (He points to the two joints on the doll pram, Fig. 2a and b). $6 \mathrm{KT}$ : Can you see if this is equal Elias?

7 Elias: Look! There, there (Fig. 3a and b) there, there (pause) there, there (Fig. 4a and $b$ ) and there, there (pause) and there and there, and (pause) everywhere (he swipes his whole hand over the doll pram, Fig. 5).

For every "there, there" and "there and there," Elias points with his index finger to (or towards) two corresponding points on the doll pram. When Elias says "everywhere," he swipes his whole hand over the doll pram.

It is tempting to see this segment of argumentation from a rationalistic, subjective perspective and interpret the argumentation as an expression of already acquired knowledge about reflection symmetry. Instead of viewing the argumentation from a rationalistic perspective,

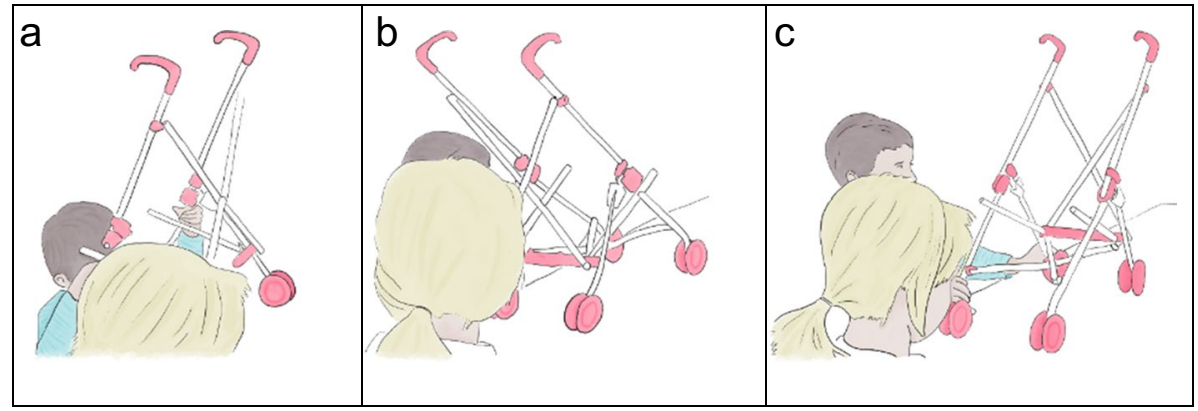

Fig. 1 a-c John's explanation in Turn 2 and 4

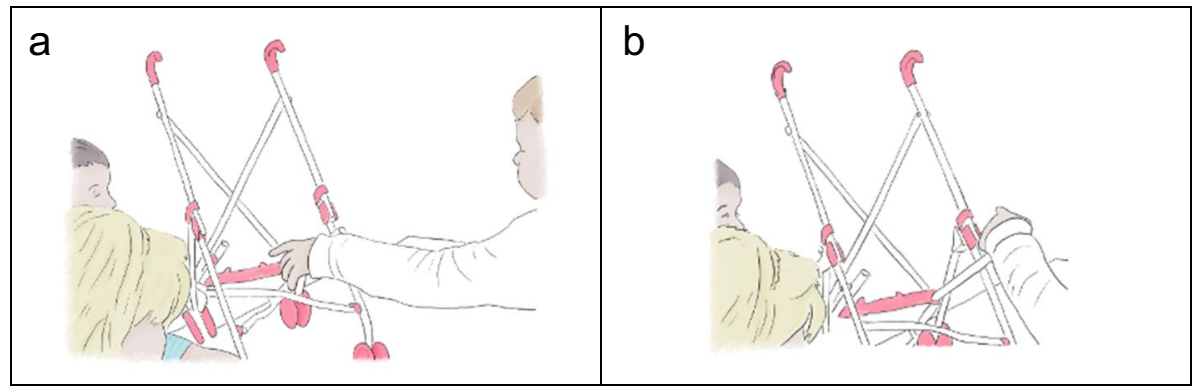

Fig. 2 a, b Elias's pointing gestures when he says "there and there" in Turn 5. He first points to the left side $\mathbf{a}$ and then to the right side of the doll pram $\mathbf{b}$ 


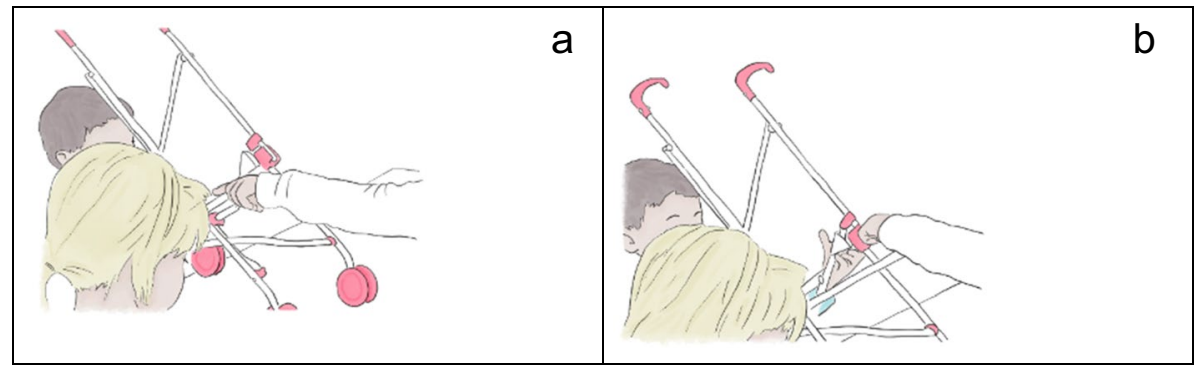

Fig. 3 a, b Elias' pointing gestures when he says "there, there" the first time in Turn 7. Elias touches the points he refers to, which are at the very bottom of the pink joints. He first points to the left joint $\mathbf{a}$ and then to the right joint $\mathbf{b}$

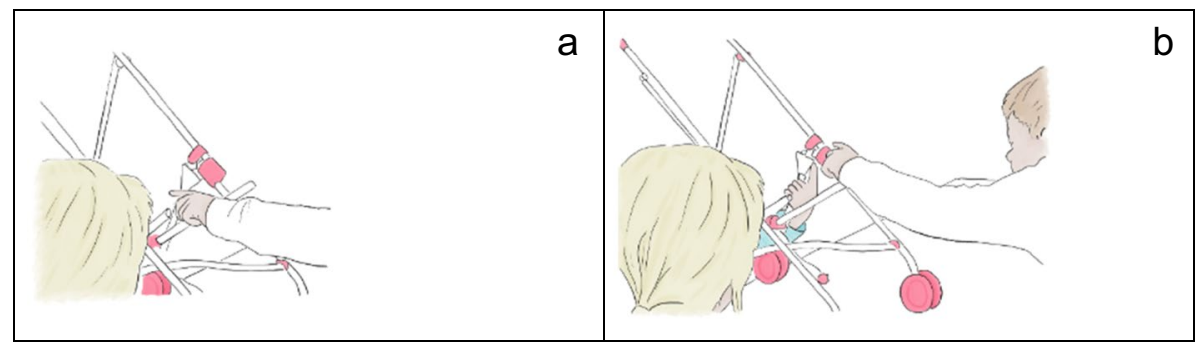

Fig. 4 a, b Elias' pointing gestures when he says "there, there" the third time in Turn 7. Now he points towards the top of the pink joints

Fig. 5 Elias' swiping hand when he says "everywhere" in Turn 7

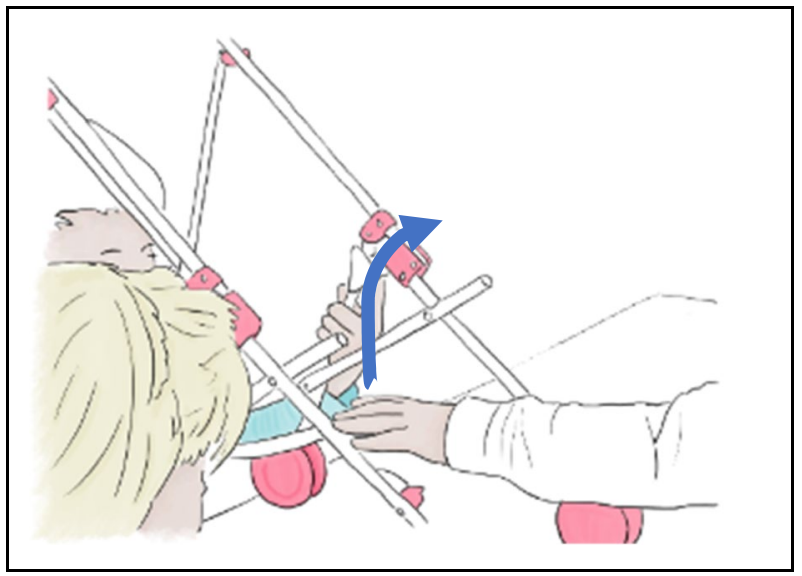

where gesture and speech are mere expressions of thought, the materialist approach to embodied cognition allows us to see the emergence of the mathematical idea through the actual physical activity. The idea of reflection symmetry has, of course, most likely at least, already started to emerge in children's consciousness through the previous activity, when the KT, the 
children, the shapes, the sketch, and the mirror interact. But, as I intend to show in the analysis, the idea of reflection symmetry continues to emerge and become sensible through the activity, at least for Elias.

Before I present the analysis, I note that, in the segment above, it seems that John considers reflection symmetry on the whole doll pram (3D). However, Elias seems to consider the 2D symmetry on the frontside of the doll pram that faces him (he operates only with corresponding points on the frontside), perhaps because the doll pram is almost out of reach.

\subsection{Synchronic analysis}

The segment starts with the KT who challenges John to explain why he thinks the doll pram is equal on two sides (note: the KT asks whether the doll pram is equal on two sides (a yes/no question), but John interprets this as a request to explain why). First, John lifts the doll pram in the air, in a straightforward position from his own point of view, and then he nods his head and says "there" (Fig. 1a). The word "there" is precisely synchronised with the nodding towards the doll pram, and I interpret that John presents the whole doll pram as an explanation for why the doll pram is equal on two sides. It is quite common that young children justify their geometrical insights by referring to the physical object itself (e.g., van Hiele \& van Hiele, 1958). Then John turns the doll pram 90 degrees showing the left side of the doll pram and says "there" (Fig. 1b). There is a little pause while he keeps his gaze at the doll pram. Then he turns the doll pram 180 degrees showing the right side of the doll pram and says "there" (Fig. 1c). The coordination of these actions (the second and third "there," synchronised with his use of the doll pram) may also be seen as a justification for why the doll pram is equal on two sides. This time John provides a concrete example of the equality.

Then Elias intensifies his participation in the activity and elaborates on John's explanation. Elias points his index finger towards two corresponding "points"4 on the doll pram (the joints) and synchronically says "and there and there" (Fig. 2a and b). This coordination of gestures and words may also be seen as an example of equality; the left side is equal to the right side.

The KT responds to Elias' contribution and asks Elias if he can check whether the doll pram is equal. Elias starts, quite slow and accurate, to present pairs of reflection symmetrical points. With his index finger, he slowly points to two and two corresponding points on the doll pram, synchronised with the words "there, there." The first "there, there," after the KT's request, is precisely synchronised with the related pointing gestures (Fig. 3a and b). Moreover, Elias touches the points he refers to. The second "there, there" and the related pointing gestures are similarly precise. Again, he touches the points while he synchronically says "there, there." The third "there, there" is still synchronised with the related pointing gestures; however, now Elias does not touch the points he refers to, and he increases the tempo a little (Fig. 4a and b). The two last "there, there" and "there and there" are less accurately synchronised with the related pointing gestures. Elias has increased the tempo, and the pointing gestures are a bit delayed compared to the utterance. Thus, it is quite difficult to know exactly what points Elias refers to. However, he points first towards the left

\footnotetext{
${ }^{4}$ Elias does not just point to points (in the mathematical sense), but to details on the doll pram that for him
} looks the same. 
side of the doll pram and then towards the right side of the doll pram, moving his hand perpendicular to the symmetry line. My interpretation is that Elias does not focus on two particular points on the doll pram, rather to two imaginary points. It seems that he does not point directly to two corresponding points on the doll pram, rather he has moved his perception away from the doll pram into the imaginary.

At the end of the segment, Elias swipes his hand and says "everywhere" (Fig. 5). The adverb "everywhere" synchronised with the swiping hand gesture signifies that Elias has grasped a general. However, it is impossible to fully understand the meaning of the word "everywhere" and the synchronised swiping hand gesture without the previous activity. In the diachronic analysis below, I will explore this relationship.

Although I focus on moment-to-moment coordination of signs, there is always movement in activity, which is essential for the emergence of meaning. For example, the synchronisation of the swiping hand gesture and the word "everywhere" happens over a short period of time. Moreover, when Elias points to two corresponding points on the doll pram, he first points at one point on one side, and then he moves his index finger in a straight line, perpendicular to the (invisible) symmetry line, to the corresponding point on the other side. The movement from one side to the other signifies how the two points corresponds.

\subsection{Diachronic analysis}

I now focus attention on the movement of the whole activity in order to explore what facilitates Elias' move into the imaginary and the establishment of a new point of view.

When John says "there" the first time, he presents the whole doll pram as an explanation for why the doll pram is equal on two sides. In the subsequent explanation, the coordination of John's actions is more detailed; he shows two sides of the doll pram and provides an example of the symmetrical equality. When Elias intensifies his participation in the activity, he brings in more details; he uses his index finger to indicate specific points on the doll pram to provide examples of corresponding points. This coordination of semiotic means finally accumulates into a general statement; Elias swipes his hand over the doll pram while he says "everywhere." This assemblage may be seen as a semiotic contraction, where the development of the activity yields a new, more compact unity: the swiping hand gesture and the word "everywhere."

There are several aspects, I hold, that contribute to this development. For example, the rhythm that is created by the repetitive "there, there" and the related pointing gestures seems essential for the movement of the activity. The rhythm indicates that there is a regularity or continuation of "something" and it seems to give the children (especially Elias in this case) possibilities to imagine what comes next (cf. Radford, 2015). The rhythm signifies pairs of reflection symmetrical points that continue to emerge and seems to move Elias into the imaginary. Moreover, the words "and" that can be found between some of Elias' "there, there" utterances connect the examples (the corresponding points) together. Furthermore, there is a slight increase in tempo in Elias' repetitive gesturing.

Elias points to a finite number of corresponding points, but he does not generalise from the finite number of examples; the rhythmic gesture, coordinated with "there, there" and the increase in tempo, signifies, I hold, that there are lots of corresponding points that continue to emerge. The coordination of semiotic means, over time, culminates in a generalisation 
when Elias swipes his hand over the trolley and says "everywhere." The word "everywhere" in itself does not signify a generalisation. Rather, the swiping hand gesture appears to collect all the points, both the specific concrete points on the doll pram, and the manifold of points that Elias (seems to) imagines exist. So, the swiping hand gesture in conjunction with the word "everywhere" signifies a general. Through the repetitive and rhythmic utterances and gestures, it seems that Elias establishes a new point of view (cf. van Oers $\&$ Poland, 2007), which then guides his further actions; what Elias perceives through his rhythmic gestures and utterances promotes him to swipe his hand and say "everywhere." Elias moves from the particular (specific points on the doll pram), towards the imaginary (imaginary points) and finally generalises that each point on one side of the doll pram has a corresponding point on the other side of the doll pram.

\subsection{Comparison between John and Elias' abstractions}

When John explains why the doll pram is equal on two sides, he pauses between the second and third "there" and therefore seems a bit uncertain. However, considering what happens before the segment analysed above, it seems that John carefully examines the doll pram before he takes it back to the table. John first examines the doll pram from a straightforward position, and then he examines the left and the right side of the doll pram (Fig. 6a-c). This indicates that his choice is not random but is carefully considered. This further indicates that, when John explains why the doll pram is equal on two sides in the segment above, he already knows that the doll pram is "equal on two sides," which is the expression that the KT uses to mean reflection symmetry. It seems that John knows on a sensory level and that the idea has not yet emerged at the linguistic level (cf. Thom \& Roth, 2011).

While John only explains his abstraction, which most likely happened in the previous joint activity, it seems that Elias, on the other hand, reaches a new point of view through his explanation. The most prominent difference between John and Elias is that while Johns' explanation resides in the sensory realm, Elias expands his semiotic repertoire in describing the symmetry. For John, the idea has not yet reached the realm of verbal language, while for Elias, the idea is at the brink of moving into the realm of verbal language.

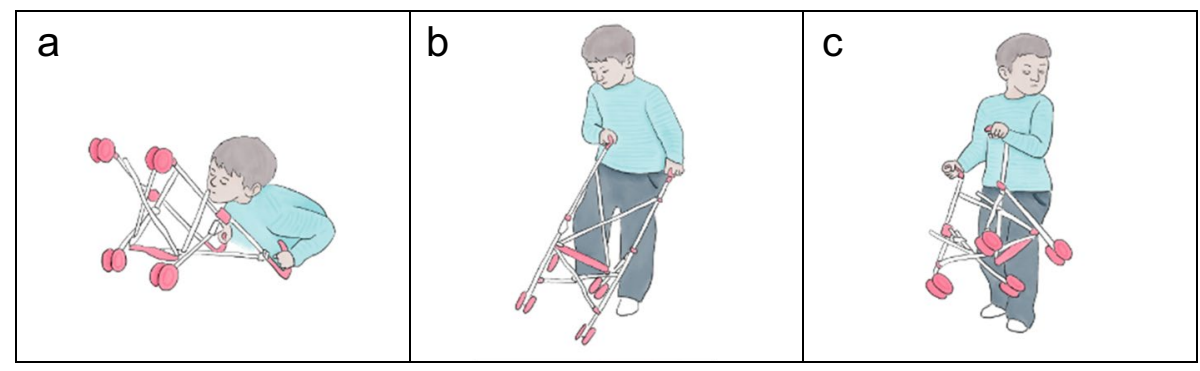

Fig. 6 a-c John examines the doll pram before he takes it back to the table 


\section{Discussion and concluding remarks}

Writing about what counts as abstractions, using an example of learning about threedimensional shapes, de Freitas and Sinclair (2014) argue that: "If abstraction is taken to be a process that depends on moving from visual perceptions of shapes to succinct verbal descriptions (listing the necessary properties of the shapes, for example), then there is no amount of moving with the hands that will count as abstraction" (p. 162). In the segment examined above, it is striking how few words are used in the two boys' explanation. Except for Elias' last utterance "everywhere," the only words that are used are "there" and "and." Thus, the abstraction that takes place in this segment cannot be accounted for in linguistic terms only.

Returning to the research question, "What characterises the process of grasping a general?", it is clear that the process is not characterised by its extended use of language. I now argue that it is gestures, bodily actions, and rhythm, in conjunction with spoken words, that allow John and especially Elias to grasp a general and establish a new point of view or, as Davydov (1972/1990) would say, to ascend to the concrete - the pram remains the pram but in the new point of view Elias sees and acts on ${ }^{5}$ the pram from the position of someone who has grasped its symmetric properties. First, John's bodily actions and his use of the doll pram signify how the two sides of the doll pram relate. Then Elias' pointing gestures, including the movement from one side to the other, construct relations between points and signify how they correspond. Moreover, rhythm plays an important role in the process. Rhythm, as the temporal recurrence of "something," in this case the recurrence of corresponding points, allows Elias to imagine how corresponding points will continue to emerge (cf. Radford, 2015). Through the activity, John and Elias, in interaction with the doll pram, construct new relations and new material configurations. Rhythm and gestures, together, structure the process where new relations in the concrete are created and are thus essential for connecting different aspects of the concrete whole (cf. Hershkowitz et al., 2001; Ozmantar \& Monaghan, 2007; van Oers, 2001; van Oers \& Poland, 2007). Rhythm and gestures, together with the words "there and there," allow Elias to move from the particular into the imaginary and further to a general. Although my study applies to spatial concepts, as opposed to algebraic ones, there are similarities between my work and Radford's (2008, 2013, 2015, 2018) work on pattern generalisations. Radford illustrates how gestures and rhythm, in conjunction with other semiotic means, gradually move students' awareness towards grasping a general, that is, how students first point to the concrete features of the sensory manifold and then how, for example, repeated gestures gradually move students' awareness to the imaginary and finally to recognising an algebraic structure.

At the end of the segment, Elias' new point of view is signified by the adverb everywhere and a swiping hand gesture. It is the adverb everywhere that endows the phenomenon its full generality. However, the word everywhere is meaningless without the swiping hand gesture and the previous activity. This illustrates an essential feature of what Radford $(2008,2013,2018)$ calls semiotic contraction. The flow of movement from the previous activity does not vanish or disappear, rather it is subsumed and contracted into a new unity. In this case, the previous activity (i.e., the repeated pointing gestures and the words "there and there") does not vanish, but is contracted into the adverb everywhere and the swiping hand gesture. This mechanism is an essential feature in dialectic materialism, as emphasised by Davydov (1972/1990):

\footnotetext{
5 Seeing and acting on here is viewed as a dialectical to and from rather than a linear sequence.
} 
Within the evolving natural whole, all things are constantly changing, passing into other things, vanishing. But each thing, according to dialectics, does not merely change or disappear - it passes into its own other, which, within some broader interaction of things, proceeds as a necessary consequence of the being of the thing that has vanished. (p. 253)

This study extends Radford's work by evidencing this phenomenon with kindergarten children and in a geometric context.

Although the abstraction of both boys seems to appear mainly on the sensory and gestural level (cf. Thom \& Roth, 2011), there is a significant difference between the two boys' abstraction. While John's explanation resides mainly in the sensory realm, Elias expands his semiotic repertoire in describing the symmetry. In Radford's studies on pattern generalisations, the students move from factual to contextual and finally to symbolic generalisation, where each generalisation is tied to different semantic structures (gestural, linguistic, symbolic). The generalisation in this paper is closest to what Radford (2018) calls factual generalisation, because rhythmic gestures are dominant throughout the process. However, the study also illustrates how, for Elias, the idea is on the brink of moving into the realm of verbal language. Elias can use the adverb everywhere to refer to how each point on one side corresponds with another point on the other side, but he is not able to explain this relationship with sentences yet - or at least he does not display his ability to explain.

The study also gives insights into how symmetry perception develops, from seeing symmetry as "a whole" to paying attention to particularities which contributes to a mathematical way of perceiving reflection symmetry. Much research on symmetry perception, conducted within psychophysical studies, indicates that symmetry is an organising means for how humans visually perceive the material world (Treder, 2010). However, this line of research does not consider how our perception is a result of stimuli already filtered by cultural meanings conveyed by language and other cultural semiotic systems (Radford, 2010). Arnheim (1969) points to the tension between perceiving symmetry as a whole and its articulation. However, to perceive symmetry mathematically is precisely to recognise how elements connect to the whole. Thus, a path through its articulation (gestural or linguistic) is essential. At the end of the segment, Elias, again, perceives reflection symmetry as a whole; however, this time, the whole is endowed with cultural and mathematical meaning. This study therefore illustrates how, through activity, human "form of sensing and reflecting are culturally transformed" (Radford, 2013, p. 159).

The results in this study also extend the work of Hershkowitz et al. (2001). It can be argued that Elias is "vertically reorganising previously constructed mathematics into a new mathematical structure" (Hershkowitz et al., 2001, p. 202). This novel mathematical structure is, by Hershkowitz et al. (2001), considered mental structures that allow recognition of similar structures in the future. In this case, the novel mathematical structure, or the new point of view, is also a mental structure, but in a strictly embodied sense. In terms of the $\mathrm{RBC}$ model, Elias (R)ecognises equal points on the doll pram which he (B)uilds-with other recognisable points on the doll pram in achieving the goal of answering the KT's question. Through his concrete actions, and how these actions are synchronically and diachronically related, Elias (C)onstructs a new mathematical structure. The structure is brought to life or materialised in the very moment it is accomplished through Elias' verbal and non-verbal actions. The new structure is not a mere mental structure in the head but is situated in concrete activity in between the sensing subject and the sensed object (cf. Radford, in press).

The view on abstraction that is proposed in this paper, as establishing a new point of view, aligns with Davydov's dialectical perspective and takes into account three things. 
First, it does not consider abstract thinking as a sort of decontextualised higher order thinking, rather it is viewed as an emergent and context-bound process, as a genuine part of children's concrete embodied activities. Although Elias seems to move into the imaginary, it is still an imagination of the concrete properties of the doll pram. The rhythm allows him to imagine that there are lots of corresponding points on the doll pram. The new point of view is also tied to the specific context; each point on one side of the doll pram has a corresponding point on the other side of the doll pram. Second, abstraction as a point of view stresses the subjective side of the sensuous activity, but it is not only a matter of what the child visually sees, rather it is a visual, auditory, kinaesthetic, and tactile perception of the dynamic structure in the concrete realm. The symmetrical properties of the doll pram are brought to life through the concrete activity and sensed by Elias. This new perspective is a sensuous perception that continuously emerges and changes through activity and is dialectically related to the child's verbal and non-verbal actions. Through the activity, a new perspective emerges, and simultaneously new actions (including physical movements) are created. Using the terms of Nemirovsky et al. (2020), one could say that the abstraction includes an establishment of new sensorimotor qualities. Third, I see abstraction not only as a process of knowing but as a process that is entangled with the process of becoming. It is not only the mathematical structure that is materialised through activity, but the subject also takes up a position in the world and through activity co-produces itself. This is illustrated by how Elias' form of sensing and acting is culturally transformed; Elias' perception (and ways of acting) of reflection symmetry develops over the course of activity. The point of view is not a static entity, it is a sensuous self-reflexive entity always in a state of flux.

Acknowledgements I am grateful to John Monaghan for questions, comments, and suggestions on earlier versions of this paper. I also thank three anonymous reviewers for their helpful comments and suggestions for the revision which helped to improve the quality of the paper. Moreover, I thank Thomas Andersen for making the sketches used in the result section and the KT and the children who participated in the study.

Funding This paper is a result of a research project, called the Agder Project, funded by the Research Council of Norway (NFR no. 237973), The Sørlandet Knowledge Foundation, The Development and Competence Fund of Aust-Agder, Vest-Agder County, Aust-Agder County, University of Agder, and University of Stavanger.

Open Access This article is licensed under a Creative Commons Attribution 4.0 International License, which permits use, sharing, adaptation, distribution and reproduction in any medium or format, as long as you give appropriate credit to the original author(s) and the source, provide a link to the Creative Commons licence, and indicate if changes were made. The images or other third party material in this article are included in the article's Creative Commons licence, unless indicated otherwise in a credit line to the material. If material is not included in the article's Creative Commons licence and your intended use is not permitted by statutory regulation or exceeds the permitted use, you will need to obtain permission directly from the copyright holder. To view a copy of this licence, visit http://creativecommons.org/licenses/by/4.0/.

\section{References}

Arnheim, R. (1969). Visual thinking. University of California Press.

Arzarello, F., Paola, D., Robutti, O., \& Sabena, C. (2009). Gestures as semiotic resources in the mathematics classroom. Educational Studies in Mathematics, 70(2), 97-109. https://doi.org/10.1007/ s10649-008-9163-Z

Bautista, A., \& Roth, W. M. (2012). The incarnate rhythm of geometrical knowing. The Journal of Mathematical Behavior, 31(1), 91-104. https://doi.org/10.1016/j.jmathb.2011.09.003 
Breive, S. (2017). Kindergarten children's argumentation in reflection symmetry: The role of semiotic means. In T. Dooley \& G. Gueudet (Eds.), Proceedings of the Tenth Congress of the European Society for Research in Mathematics Education (pp. 1837-1844). Dublin City University and ERME.

Breive, S. (2019). Processes of mathematical inquiry in kindergarten. (PhD). University of Agder.

Breive, S. (2020). The materialisation of children's mathematical thinking through organisation of turntaking in small group interactions in kindergarten. In M. Carlsen, I. Erfjord, \& P. S. Hundeland (Eds.), Mathematics education in the early years: Results from the POEM4 Conference, 2018 (pp. 281-299). Springer.

Davydov, V. V. (1990). Soviet studies in mathematics education: Vol. 2. Types of generalization in instruction: Logical and psychological problems in the structuring of school curricula (J. Kilpatrick, Ed., \& J. Teller, Trans.). National Council of Teachers of Mathematics. (Original work published 1972).

De Freitas, E., \& Sinclair, N. (2014). Mathematics and the body: Material entanglements in the classroom. Cambridge University Press.

Elia, I., \& Evangelou, K. (2014). Gesture in a kindergarten mathematics classroom. European Early Childhood Education Research Journal, 22(1), 45-66. https://doi.org/10.1080/1350293X.2013.865357

Hershkowitz, R., Schwarz, B. B., \& Dreyfus, T. (2001). Abstraction in context: Epistemic actions. Journal for Research in Mathematics Education, 32(2), 195-222.

Hiebert, J., \& Lefevre, P. (1986). Conceptual and procedural knowledge in mathematics: An introductory analysis. In J. Hiebert (Ed.), Conceptual and procedural knowledge: The case of mathematics (pp. 1-27). Lawrence Erlbaum.

Nemirovsky, R., Ferrara, F., Ferrari, G., \& Adamuz-Povedano, N. (2020). Body motion, early algebra and the colours of abstraction. Educational Studies in Mathematics, 104(2), 261-283. https://doi.org/10. 1007/s 10649-020-09955-2

Noss, R., Healy, L., \& Hoyles, C. (1997). The construction of mathematical meanings: Connecting the visual with the symbolic. Educational Studies in Mathematics, 33(2), 203-233.

Núñez, R. E., Edwards, L. D., \& Matos, J. F. (1999). Embodied cognition as grounding for situatedness and context in mathematics education. Educational Studies in Mathematics, 39(1-3), 45-65.

Ozmantar, M. F., \& Monaghan, J. (2007). A dialectical approach to the formation of mathematical abstractions. Mathematics Education Research Journal, 19(2), 89-112.

Palatnik, A., \& Abrahamson, D. (2018). Rhythmic movement as a tacit enactment goal mobilizes the emergence of mathematical structures. Educational Studies in Mathematics, 99(3), 293-309. https://doi. org/10.1007/s10649-018-9845-0

Radford, L. (2008). Iconicity and contraction: A semiotic investigation of forms of algebraic generalizations of patterns in different contexts. ZDM - the International Journal on Mathematics Education, 4O(1), 83-96. https://doi.org/10.1007/s11858-007-0061-0

Radford, L. (2009). Why do gestures matter? Sensuous cognition and the palpability of mathematical meanings. Educational Studies in Mathematics, 70(3), 111-126. https://doi.org/10.1007/s10649-008-9127-3

Radford, L. (2010). The eye as a theoretician: Seeing structures in generalizing activities. For the Learning of Mathematics, 30(2), 2-7.

Radford, L. (2013). Sensuous cognition. In D. Martinovic, V. Freiman, \& Z. Karadag (Eds.), Visual mathematics and cyberlearning (pp. 141-162). Springer.

Radford, L. (2015). Rhythm as an integral part of mathematical thinking. In M. Bockarova, M. Danesi, D. Martinovic, \& R. Núñez (Eds.), Mind in mathematics: Essays on mathematical cognition and mathematical method (pp. 68-85). LINCOM GmbH.

Radford, L. (2018). The emergence of symbolic algebraic thinking in primary school. In C. Kieran (Ed.), Teaching and learning algebraic thinking with 5- to 12-year-olds: The global evolution of an emerging field of research and practice (pp. 3-25). Springer.

Radford, L. (in press). Sensed objects, sensing subjects: Embodiment from a dialectical materialist perspective. In L. Edwards \& C. Krause (Eds.), The Body in Mathematics. Sense/Brill.

Radford, L., \& Sabena, C. (2015). The question of method in a Vygotskian semiotic approach. In A. BiknerAhsbahs, C. Knipping, \& N. Presmeg (Eds.), Approaches to Qualitative Research in Mathematics Education (pp. 157-182). Springer.

Roth, W.-M. (2011). Geometry as objective science in elementary classrooms: Mathematics in the flesh. Routledge.

Sabena, C. (2018). Exploring the contribution of gestures to mathematical argumentation processes from a semiotic perspective. In G. Kaiser, H. Forgasz, M. Graven, A. Kuzniak, E. Simmt, \& B. Xu (Eds.), Invited Lectures from the 13th International Congress on Mathematical Education (pp. 541-559). Springer. 
Sinclair, N., Chorney, S., \& Rodney, S. (2016). Rhythm in number: Exploring the affective, social and mathematical dimensions of using Touch Counts. Mathematics Education Research Journal, 28(1), 31-51. https://doi.org/10.1007/s13394-015-0154-y

Thom, J. S., \& Roth, W. M. (2011). Radical embodiment and semiotics: Toward a theory of mathematics in the flesh. Educational Studies in Mathematics, 77(2-3), 267-284. https://doi.org/10.1007/ s10649-010-9293-y

Treder, M. S. (2010). Behind the looking-glass: A review on human symmetry perception. Symmetry, 2(3), 1510-1543. https://doi.org/10.3390/sym2031510

van Hiele, P. M., \& van Hiele, D. (1958). A method of initiation into geometry. In H. Freudenthal (Ed.), Report on methods of initiation into geometry (pp. 67-80). Walters.

Van Oers, B. (2001). Contextualisation for abstraction. Cognitive Science Quarterly, 1(3), 279-305.

Van Oers, B., \& Poland, M. (2007). Schematising activities as a means for encouraging young children to think abstractly. Mathematics Education Research Journal, 19(2), 10-22. https://doi.org/10.1007/ BF03217453

Publisher's note Springer Nature remains neutral with regard to jurisdictional claims in published maps and institutional affiliations. 